\title{
Evolutionary genomics of APSE: a tailed phage that lysogenically converts the bacterium Hamiltonella defensa into a heritable protective symbiont of aphids
}

\author{
Bret M. Boyd ${ }^{1,2^{*}}$, Germain Chevignon ${ }^{3}$, Vilas Patel ${ }^{1}$, Kerry M. Oliver ${ }^{1}$ and Michael R. Strand ${ }^{1 *}$
}

\begin{abstract}
Background: Most phages infect free-living bacteria but a few have been identified that infect heritable symbionts of insects or other eukaryotes. Heritable symbionts are usually specialized and isolated from other bacteria with little known about the origins of associated phages. Hamiltonella defensa is a heritable bacterial symbiont of aphids that is usually infected by a tailed, double-stranded DNA phage named APSE.

Methods: We conducted comparative genomic and phylogenetic studies to determine how APSE is related to other phages and prophages.

Results: Each APSE genome was organized into four modules and two predicted functional units. Gene content and order were near-fully conserved in modules 1 and 2, which encode predicted DNA metabolism genes, and module 4, which encodes predicted virion assembly genes. Gene content of module 3, which contains predicted toxin, holin and lysozyme genes differed among haplotypes. Comparisons to other sequenced phages suggested APSE genomes are mosaics with modules 1 and 2 sharing similarities with Bordetella-Bcep-Xylostella fastidiosa-like podoviruses, module 4 sharing similarities with P22-like podoviruses, and module 3 sharing no similarities with known phages. Comparisons to other sequenced bacterial genomes identified APSE-like elements in other heritable insect symbionts (Arsenophonus spp.) and enteric bacteria in the family Morganellaceae.
\end{abstract}

Conclusions: APSEs are most closely related to phage elements in the genus Arsenophonus and other bacteria in the Morganellaceae.

Keywords: Virus, Bacteria, Mutualism, Aphid, Parasitoid

\section{Background}

Viruses that infect bacteria (phages) are the most numerous biological entities on Earth [1-3]. Phages also affect many important ecological and evolutionary processes through the mortality effects they have on bacteria [4, 5] and the horizontal transfer of genes that enhance

*Correspondence: boydbm@vcu.edu; mrstrand@uga.edu

1 Department of Entomology, University of Georgia Athens, Athens, GA, USA

Full list of author information is available at the end of the article bacterial fitness [6, 7]. Most known phages infect freeliving bacteria that live in soil, water or other habitats but a few have been identified that infect heritable symbionts of eukaryotes [8-14].

Heritable symbionts associated with insects include obligate mutualists that provide essential benefits to their hosts, facultative mutualists that provide conditional benefits, and reproductive parasites [10, 15-30]. Aphids (Hemiptera:Sternorrhyncha:Aphidoidea) are insects that commonly harbor multiple heritable symbionts $[10$, original author(s) and the source, provide a link to the Creative Commons licence, and indicate if changes were made. The images or other third party material in this article are included in the article's Creative Commons licence, unless indicated otherwise in a credit line to the material. If material is not included in the article's Creative Commons licence and your intended use is not permitted by statutory regulation or exceeds the permitted use, you will need to obtain permission directly from the copyright holder. To view a copy of this licence, visit http://creativecommons.org/licenses/by/4.0/. The Creative Commons Public Domain Dedication waiver (http://creativeco mmons.org/publicdomain/zero/1.0/) applies to the data made available in this article, unless otherwise stated in a credit line to the data. 
31-33]. Approximately one third of sampled aphid species also harbor the facultative mutualist Hamiltonella defensa, which is a $\gamma$-Proteobacterium (order Enterobacterales, family Yersiniaceae) that primarily lives extracellularly in the hemocoel. $H$. defensa also infects other sternorrhynchan hemipterans [34-41]. H. defensa conditionally enhances the fitness of the pea aphid, Acyrthosiphon pisum, and other species by conferring resistance to parasitoid wasps that kill hosts by laying eggs into their bodies [18, 40, 42-45].

Several strains of $H$. defensa have been identified that differ in the levels of parasitoid resistance they confer upon the pea aphid [46-49]. Resistance is associated with infection by a double-stranded (ds) DNA phage that was originally named $A$. pisum secondary endosymbiont (APSE) [8] and was later found to infect $H$. defensa in aphids and other hemipterans [12, 36, 38, 41, 44, 45, 50-54]. Multiple APSE haplotypes were identified that encode different toxin genes with potential roles in mediating resistance to parasitoids $[38,51,55,56]$. In $A$. pisum, $H$. defensa strains infected by a haplotype named APSE3 confer high levels of resistance by killing Aphidius ervi wasps during the egg stage, while strains infected by APSE2 and APSE8 confer an intermediate level of resistance by killing wasps as eggs or larvae $[40,45,57]$. APSE1 is also associated with high resistance to $A$. ervi, but little is known about timing of wasp mortality [12]. H. defensa strains that are not APSE-infected confer no resistance to wasps while imposing fitness costs on aphids that suggest a shift from being a conditional mutualist to a parasite $[57,58]$.

APSEs that confer resistance to parasitoids are integrated into the main chromosome of $H$. defensa [40, 56, 59], which supports that lysogenic conversion [60] underlies the evolution of this bacterium into a protective symbiont of aphids. Persistence as a provirus also enables the vertical transmission of APSEs to aphid offspring when $H$. defensa cells are maternally acquired [46]. However, some APSEs replicate and produce virions that can horizontally transfer the viral genome to non-infected strains of $H$. defensa [8, 40, 58, 61], while some $H$. defensa strains have been horizontally transmitted between insect hosts by different mechanisms [31, 35, 50, 62-66].

Previous results support that an APSE phage infected the common ancestor of all known $H$. defensa strains [62, 67]. However, the evolutionary relationship of APSE to other phages are incompletely understood. Early results showed that APSEs produce short-tailed virions that morphologically resemble phages assigned to the family Podoviridae (order Caudovirales) while sequence analysis identified some genes with predicted functions in virion assembly that shared similarities with genes in the model podovirus Salmonella enterica P22 [8]. Subsequent studies further noted that virion assembly genes in P22 are organized into a syntenous module in several phages including APSEs, while the hosts for these phages were primarily restricted to $\gamma$-Proteobacteria in the order Enterobacterales $[68,69]$. However, low amino acid identities for most virion assembly genes suggested APSEs are among the most divergent of these P22-like phages [69], while genome-wide nucleotide homology clustered APSEs separately due to dissimilarities outside of the virion-assembly module [70]. Isolation of $H$. defensa as a specialized symbiont of sternorrhynchan hemipterans has been posited as one factor contributing to APSE divergence $[62,71]$. Previous findings $[9,72-75]$ together with more recent results [67] identified phage elements present in two other groups of insect symbionts, Arsenophonus (Morganellaceae) and Sodalis (Pectobacteriaceae), which suggest horizontal exchange events may also contribute to APSE divergence.

In this study, we identified APSEs (herein APSE1 MI47, APSE9 MI12, and APSE8 5D) in three additional strains of $H$. defensa (MI47, MI12, and 5D) from $A$. pisum. We then used these data with other previously sequenced APSE haplotypes to identify: 1) key features of APSE genomes that are shared with other tailed phages assigned to the Caudoviralis, and 2) discern potential evolutionary relationships outside of the phage elements that exist in Arsenophonus and Sodalis spp.

\section{Methods}

\section{APSEs from Hamiltonella defensa used in this study}

Complete genome assemblies for the A2C, AS3, NY26, ZA17, 5AT, MI47, MI12, and 5D strains of $H$. defensa were previously generated by establishing clonal A. pisum lines containing each strain and then establishing in vitro cultures of each strain from these aphid lines (Table 1) [30, 40, 56, 59], that allowed for single molecule real-time (SMRT) sequencing without amplification or contamination by DNA from the genomes of the aphid or another abundant endosymbiont (Buchnera) following previously described protocols for library preparation and sequencing [56]. Each $H$. defensa genome was then assembled as detailed by Chevignon et al. [56]. Each APSE genome in the above strains of $H$. defensa, the APSE1 genome that was sequenced by van der Wilk et al. [8], and the APSE MEAM and APSE MED genomes from the $H$. defensa MEAM and MED strains were aligned using MAFFT [76] in Geneious (v.10; Biomatters [77]). Protein similarities were assessed by extracting coding sequences (herein genes) followed by translation and alignment in MAFFT. Genes conserved across all haplotypes were named as designated by van der Wilk et al. [8] for APSE1 while genes present in some but not all haplotypes were named as designated in subsequent studies $[8,56]$. To assess 
Table 1 APSE haplotypes with fully sequenced genomes examined in this study

\begin{tabular}{llllllll}
\hline Haplotype & Bacterial host & Insect host & Toxin & Data type & Assembly type & References & NCBI identifier \\
\hline APSE1 & H.defensa & Acrythosiphon pisum & $s t \times B$ & Phage genome & Whole genome & {$[8]$} & NC_000935.1 \\
APSE3 AS3 & H.defensa AS3 & Acrythosiphon pisum & YD-repeat & Contig/scaffold & Whole genome & {$[56]$} & NZ_CP017610.1 \\
APSE2 5AT & H.defensa 5AT & Acrythosiphon pisum & $c d t B$ & Contig/scaffold & Whole genome & {$[56]$} & NZ_CP001277.1 \\
APSE2 NY26 & H.defensa NY26 & Acrythosiphon pisum & $c d t B$ & Contig/scaffold & Whole genome & {$[56]$} & NZ_CP017605.1 \\
APSE8 ZA17 & H.defensa ZA17 & Acrythosiphon pisum & $c d t B$ & Contig/scaffold & Whole genome & {$[56]$} & NZ_CP17613.1 \\
APSE MEAM & H.defensa MEAM & Bemisia tabaci & $c d t B$ & Contig/scaffold & Whole genome & {$[38]$} & CCVN0000000 \\
APSE MED & H.defensa MED & Bemisia tabaci & $c d t B$ & Contig/scaffold & Whole genome & {$[51]$} & GCF_000258345.2 \\
APSE1 MI47 & H.defensa MI47 & Acrythosiphon pisum & $c d t B$ & Contig/scaffold & Whole genome & This study & NZ_CP022932.1 \\
APSE9 MI12 & H.defensa MI12 & Acrythosiphon pisum & $c d t B$ & Contig/scaffold & Whole genome & This study & CP023987.1 \\
APSE8 5D & H.defensa 5D & Acrythosiphon pisum & $c d t B$ & Contig/scaffold & Whole genome & This study & NZ_CP021663.1 \\
\hline
\end{tabular}

whether frame shifts observed in $p 24$ from APSE MEAM potentially disables virus production, we used genome sequencing depth as a proxy by accessing the wholegenome shotgun sequence library from the whitefly species in the Bemisia tabaci complex that is the host for $H$. defensa MEAM (SRR3180082) [38, 78] and converting the data from SRA format to fastq using the SRA-Toolkit v.2.4.2. We then estimated sequence coverage using bowtie2 v.2.2.6 (implementing the -end-to-end option) [79] by aligning and counting reads that mapped to APSEMEAM or $H$. defensa with APSE manually removed (NZ_CP016303.1).

\section{Candidate ortholog identification}

We identified candidate orthologs by searching the NCBI non-redundant (nr) database using BLASTP [80] for each gene in the APSE3 AS3 prophage genome. Searches were limited to either entries classified as Caudovirales or $\gamma$-Proteobacteria. Results were downloaded as tab separated values and filtered to find the best hit for each gene predicted in the APSE genome. Additional searches were conducted to identify candidate homologs of genes absent in APSE3 AS3 genome, but present in other APSE genomes, including cytolethal distending toxin $(c d t B)$ found in APSE8 ZA17 and shiga toxin $(s t x B)$ found in APSE1. Additional focused BLASTP and BLASTN searches of NCBI whole genome sequence (wgs) and RefSeq genomes databases were used to identify proviral elements that shared multiple homologs with APSE. BLAST searches were conducted during January of 2021.

\section{Identification of APSE-like elements in bacterial genomes}

We used a TBLASTX search with APSE3 AS3 genes serving as queries to identify candidate APSE prophage elements in bacterial genomes. Here we searched NCBI RefSeq genomes and wgs databases targeting bacterial genomes classified as Morganelleaceae,
Enterobacteriaceae, Pectobacteriaceae, Yersiniaceae, and Erwiniaceae. Once an APSE-like prophage element was discovered, we manually identified the ends of each by comparison with other APSE genomes and then ascertained the extent of shared homologous regions by visualizing alignments using BRIG [81]. We formally compared each phage-like element to APSE using whole genome TBLASTX (V.2.9.0+) and visualizing the results using EasyFig.py (V.2.2.3) [82]. We used CD-search to identify toxin-encoding genes in the newly described APSE genome from Arsenophonus species [83]. In one instance we found a partial APSE-like element within the genome assembly of Arsenophonus nasoniae str. DSM15247. To obtain a more complete assembly of this APSE-like genome we returned to the original A. nasoniae str. DSM15247 read library. We then used aTRAM to isolate and create a draft de novo assembly of the $A$. nasonia-APSE genome [84-86]. Multiple APSE genomes were used as baits for aTRAM to collect all possible variations. Contigs obtained from aTRAM with similarity to $H$. defensa APSE were assessed for similarity to the APSE3 AS3 genome. Next, we generated a referenceguided assembly of the $A$. nasoniae-APSE genome using Geneious and both the APSE3 AS3 and APSE8 ZA17 genomes from which we extracted a consensus assembly. We then used the recently re-sequenced $A$. nasoniae str. FIN genome (NCBI assembly GCF_004768525.1) that was generated using a combination of long and short sequence reads to further assess our reference guided assembly and to determine the relative position of the APSE-like elements in the A. nasoniae genome.

\section{Phylogenetic analyses}

Orthologs of $p 19, p 24, p 41$, and $p 45$ encoded by different APSEs plus other phages and phage elements in bacteria were identified using BLASTP with full-length sequences retained and short or partial BLAST hits being rejected. 
In addition to the fully sequenced APSE haplotypes that were the focus of this study, this analysis also identified orthologs in other APSE haplotypes that had previously been partially sequenced [55]. Candidate orthologs were downloaded as nucleotide sequences, checked for length, and pseudogenes were identified. We next aligned each set of orthologs including pseudogenes using Geneious V.10 progressive translation guided alignment (translation table 11, PAM250 match/mismatch scoring matrix, gap open penalty of 12 , and gap extension penalty of $3)$. Alignments including pseudogenes were hand corrected to account for frame shifts that disrupted translation alignment processes. We then used RAxML to infer phylogenetic relationships, which uses the General Time Reversible (GTR) model of nucleotide substitutions with the option to model site heterogeneity using $\Gamma$ and invariant sites [87]. We first used PartitionFinder2 to determine the best model among models available in RAxML and optimal partitions for estimating free parameters [88]. We used $\mathrm{AIC}_{\mathrm{c}}$ to select the optimal substitution model when sample size is small (number of sites divided by maximum number of potential model parameters resulted in a low value; observed ranged from 36 to 120). The GTR $+\Gamma$ models were found to be the best fit and optimal partitions were identified. We then implemented RAxML (HPC v.8.2.8; random seed $=12,345$ ) to find the best tree with appropriate partition and model. Support for phylogenetic relationships was determined as the percent of 1000 bootstrap replicates that agreed with the best tree. Resulting trees were viewed and figures were generated using FigTree v.1.4.3 (http://tree.bio.ed. ac.uk/software/figtree/). We then repeated our phylogenetic analysis using RAxML and optimal model selection with pseudogenes removed. Since recombination could also impact our phylogenetic results, we conducted an additional phylogenetic analysis using the NeighborNet method in SplitsTree4 [89, 90] with alignments lacking pseudogenes.

\section{Results}

\section{Genome organization and sites of integration are conserved among APSE haplotypes}

Sequencing of the MI47, MI12 and 5D strains of $H$. defens $a$ showed that each contained an APSE in the main host chromosome as a single copy provirus. We then used these APSE genomes together with other sequenced haplotypes $[8,38,51,56,59]$ to compare overall features (Table 1). Total genome sizes ranged from $36,522 \mathrm{bp}$ for APSE1 MI47 to 39,884 bp for APSE2 NY26 (Fig. 1). Predicted genes further ranged from a low of 41 for APSE3 AS3 to a high of 47 for APSE2 NY26, APSE8 ZA17, and APSE8 5D (Fig. 1). BLASTP searches against the NCBI nr database yielded predicted functions for 37 genes while
13 others were classified as unknowns or hypotheticals (Fig. 1, Table 2). Comparing each predicted gene across haplotypes indicated that APSE2 5AT and APSE2 NY26 were nearly identical to one another at the amino acid level (99.8\%), whereas overall identities were lower when shared genes were compared to other haplotypes due to several genes including $p 45, p 36$ and $p 37$ (Additional file 1: Fig. S1), which had been noted to vary among APSE haplotypes in other studies [67]. We also detected frameshifts in the major capsid protein gene $(p 24)$ in APSE MEAM and APSE MED that exist as proviruses in two $H$. defensa strains present in closely related whitefly species of the Bemisia tabaci complex named MED and MEAM [38]. These frameshifts suggested $p 24$ is pseudogenized in APSE MEAM and APSE MED which combined with previously identified defects in the regulator protein I and $p 38$ (integrase) from APSE MEAM and MED [38] suggest these prophages are inactive. To further investigate this possibility, we used publicly available shotgun sequencing data generated for B. tabaci MEAM to map reads corresponding to $H$. defens $a$ and APSE. This analysis indicated $H$. defensa $(340 \times)$ and APSE $(431 \times)$ MEAM were sequenced to similar depth, which further supported this APSE haplotype persists as a prophage but likely produces no particles.

Other studies have noted that gene content and order are largely conserved among APSEs [36, 55, 67], but had not assessed genome organization from the perspective of functional units and module composition, which are characteristic of particular phage groups and suggest evolutionary constraints that maintain certain genes together because of their interactive roles in genome replication, lysogeny, virion formation and other essential functions [68-70, 91-100]. Examining our data set from these perspectives indicated that APSEs are organized into two functional units with early genes that have functions in integration, lysogeny and replication (module 1 plus $p 1$ in module 2) being on the negative strand and late genes with functions in genome packaging ( $p 2-p 5$ in module 2), virulence (module 3 ) and virion assembly (modules 4) being on the positive strand (Fig. 1, Table 1).

Integrases in temperate phages regulate site-specific recombination between the phage (attP) and bacterial (attB) attachment sites [101]. tRNA genes or sequences adjacent to tRNA genes are also common tailed-phage integration sites [102]. APSE phage (attP) and bacterial $(a t t B)$ attachment sites were previously identified, with the latter occurring in a single copy tRNA-Arg gene [55]. By comparing each APSE-infected strain of $H$. defensa to the APSE-free A2C strain we showed that this site of integration $(a t t B)$ was identical among examined strains (Fig. 1). Phage attachment attP core sequences were also almost identical among APSE haplotypes and located in 


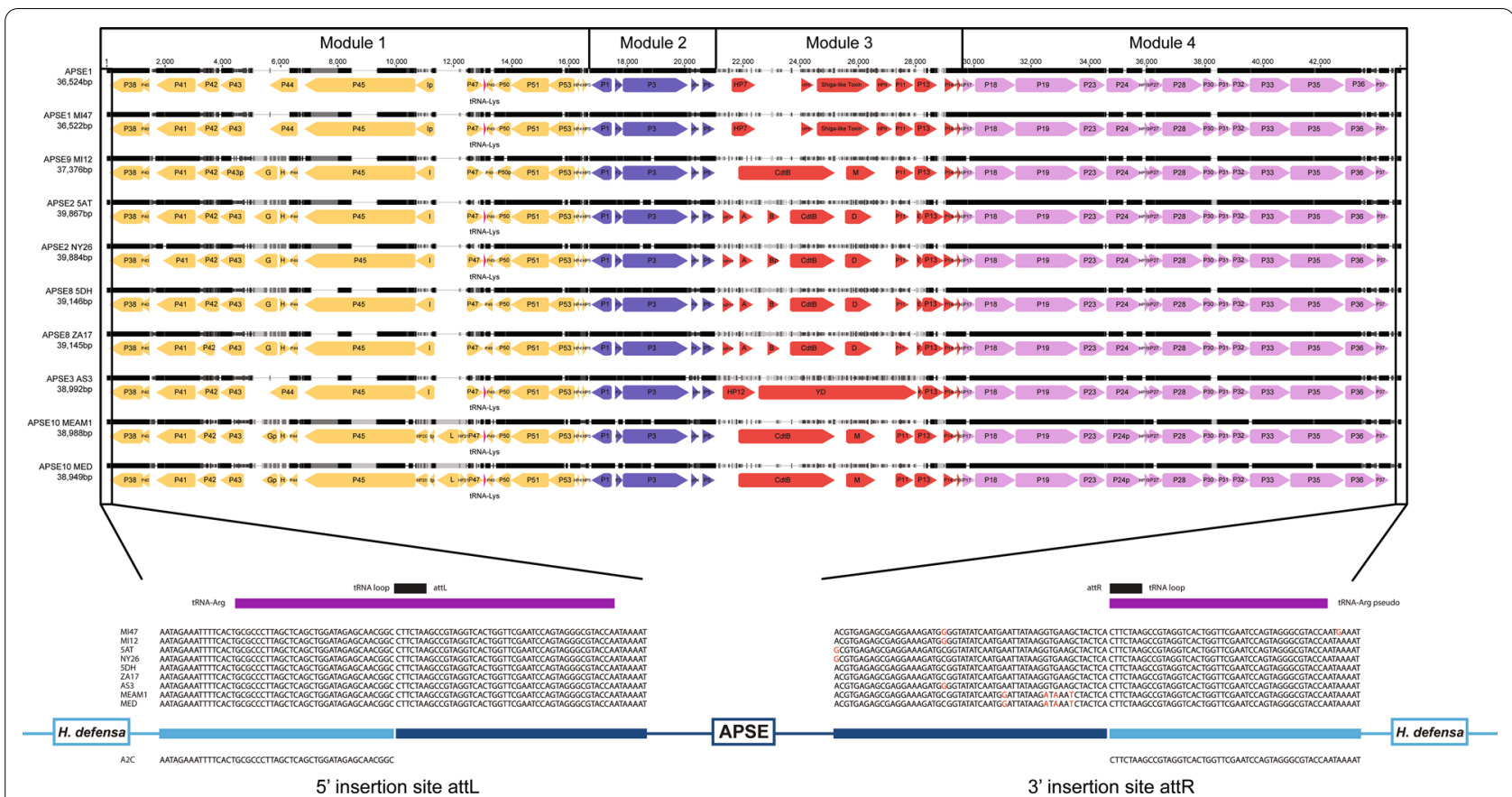

Fig. 1 Genome alignment of sequenced APSE haplotypes. The upper part of the figure schematically shows the genome for each haplotype with total size in base pairs (bp) indicated to the left, the boundaries for each module indicated at the top and the boundary for the two predicted functional units indicated at the bottom. Arrows identify predicted genes and their orientation on the positive (right) or negative strand (left) and color (yellow, blue, red, lavender) indicating module assignment. Predicted functions for each gene are summarized in Table 2. The lower part of the figure illustrates the boundaries for the attL and attR sites for each haplotype. The purple bars indicate the left and right boundaries for the $H$. defensa tRNA-Arg gene, the black bars correspond to the position of the anticodon in the tRNA-loop, the light blue bars correspond to the $H$. defensa chromosome as identified by alignment to the H. defensa A2C strain, and the dark blue bars correspond to the left and right boundaries for the integrated APSE genome

a non-coding region between $p 37$ (domain 4) and p38 (domain 1) (Fig. 1). Integration of each haplotype disrupted the host tRNA-Arg gene, but comparisons to the $\mathrm{A} 2 \mathrm{C}$ genome showed that the left $(a t t L)$ and right $(a t t R)$ boundaries of the APSE genome complemented the $H$. defensa tRNA-Arg sequence, which repaired the host gene (Fig. 1).

Our naming scheme differed from Roüil et al. [67] who named APSEs on the basis of gene content in the toxin domain (module 3 ) and variation in a domain upstream of the DNA polymerase ( $p 45)$ in module 1 . This resulted in APSE8 being classified as a subtype of APSE2. In contrast, whole genome comparisons across all four modules underlies why we continued to distinguish APSE2 from ASPE8 as distinct haplotypes. For the same reasons, we called the phage variant from MI12 $H$. defensa strain APSE9 as it too was distinct from other named APSEs across modules.

\section{Modules 1, 2 and 4 share features with other phages}

Given the conservation in gene order and content of modules 1, 2 and 4, we selected APSE3 AS3 as a model haplotype and used BLASTP to ask if any genes shared $>60 \%$ identity with predicted products from other fully sequenced viruses. Three genes in module 1 , two genes in module 2 , and seven genes in module 4 were identified that met this criterion, with each best hit being to another phage assigned to the families Podoviridae or Siphoviridae (Table 2). TBLASTX analysis corroborated previously noted similarities in gene order and content between the virion assembly module of APSEs (module 4) and P22-like phages that infect bacteria in the order Enterobacterales [68] including Salmonella virus HK620, Shigella flexneri phage Sf6, Morganella phage NV18, and S. enterica P22 [14, 71, 103-105] (Fig. 2A, B). Few similarities were detected between APSEs and these P22-like phages outside of their virion assembly modules (Fig. 2A, $\mathrm{B})$, but similarities in gene order and content were identified between APSE module 1 and 2 in podoviruses that infect hosts outside of the Enterobacterales including Xylella phage Xfas53, Burkholderia phage complex members such as BcepC6B, Bordetella phage BPP-1, and Yersinia enterocolitica phage YeP4 [105-107] (Table 2; Fig. 2B, C). In contrast, no APSE genes in module 3 shared a similar level of sequence similarity with other known viruses. 


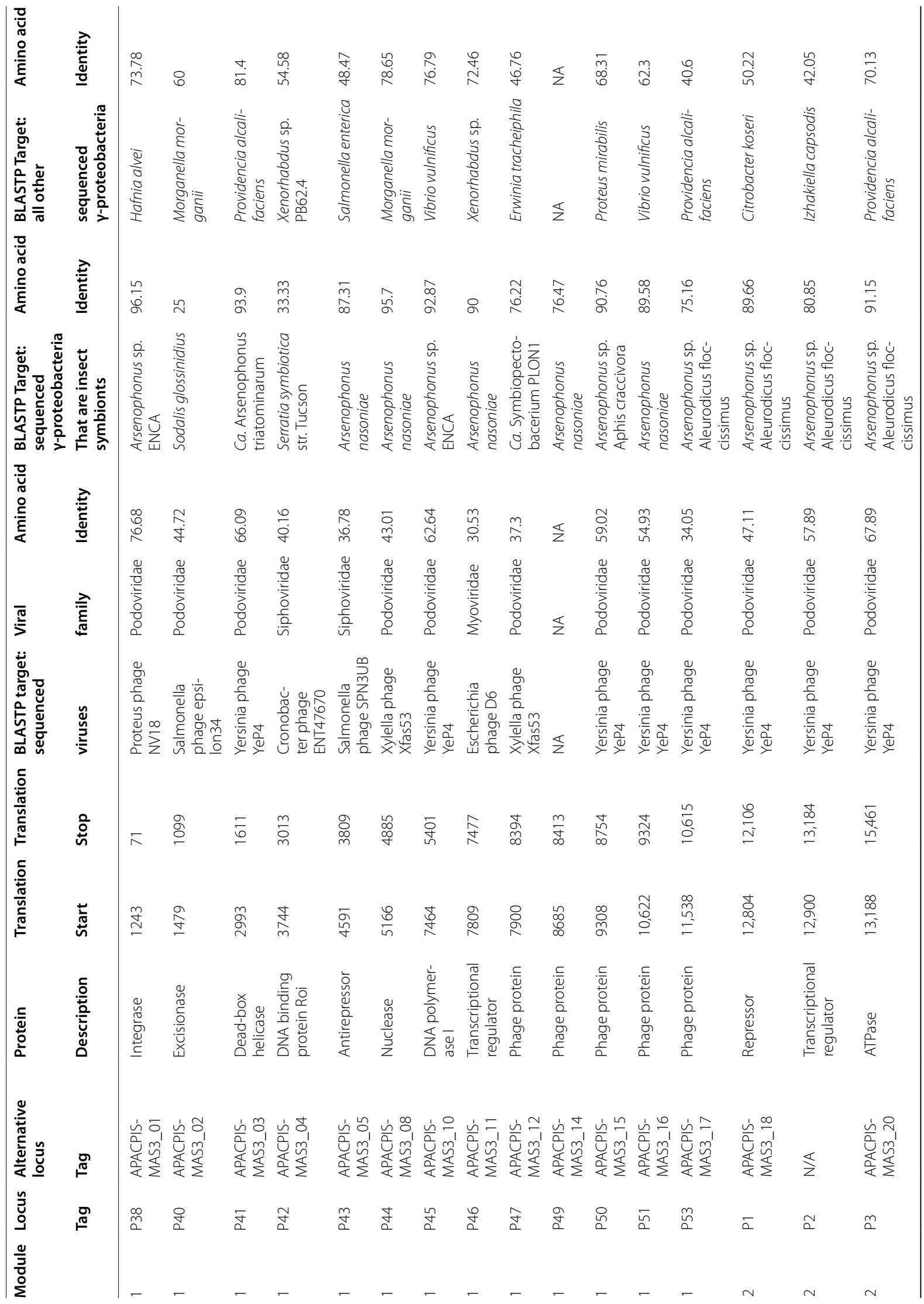



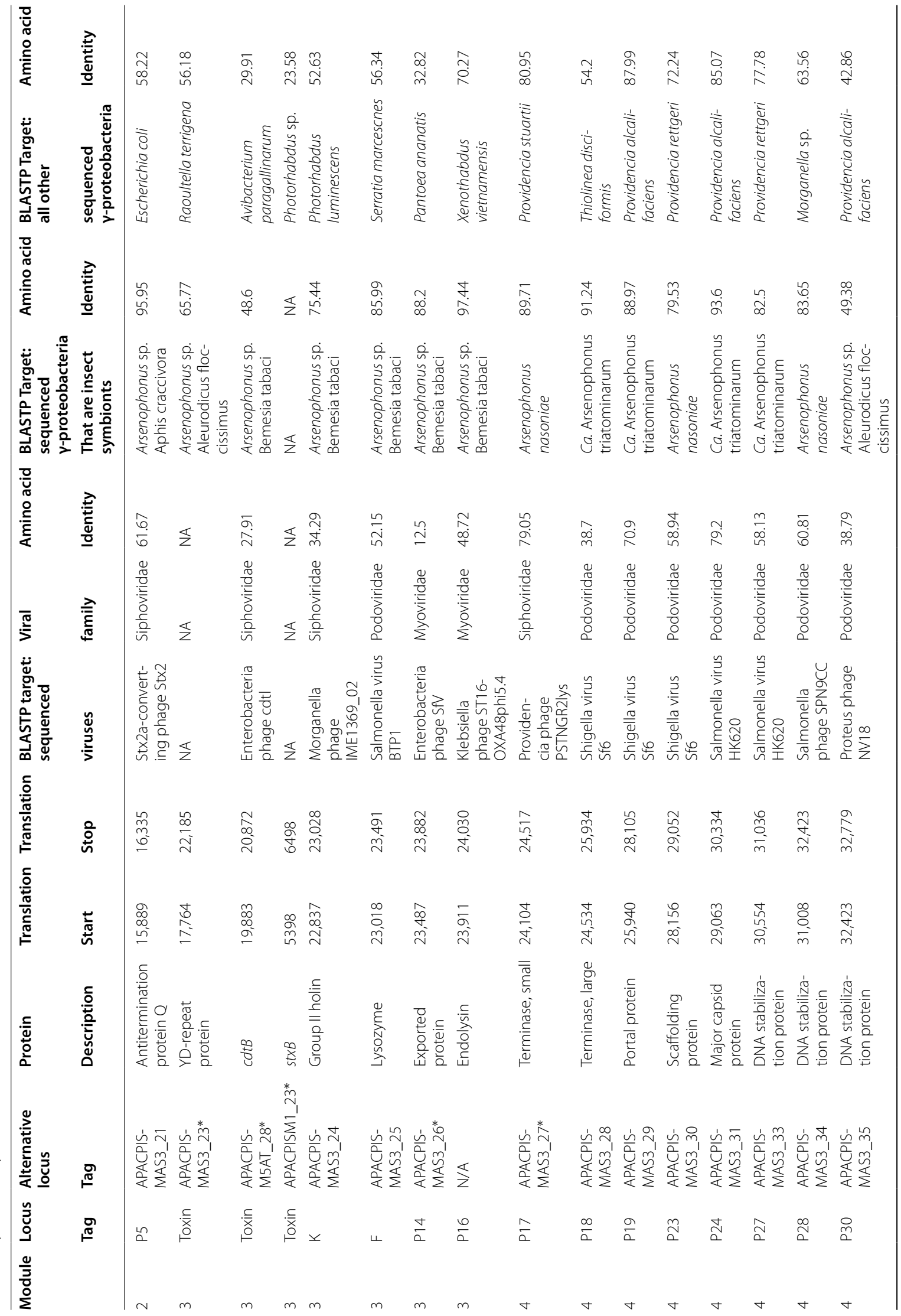


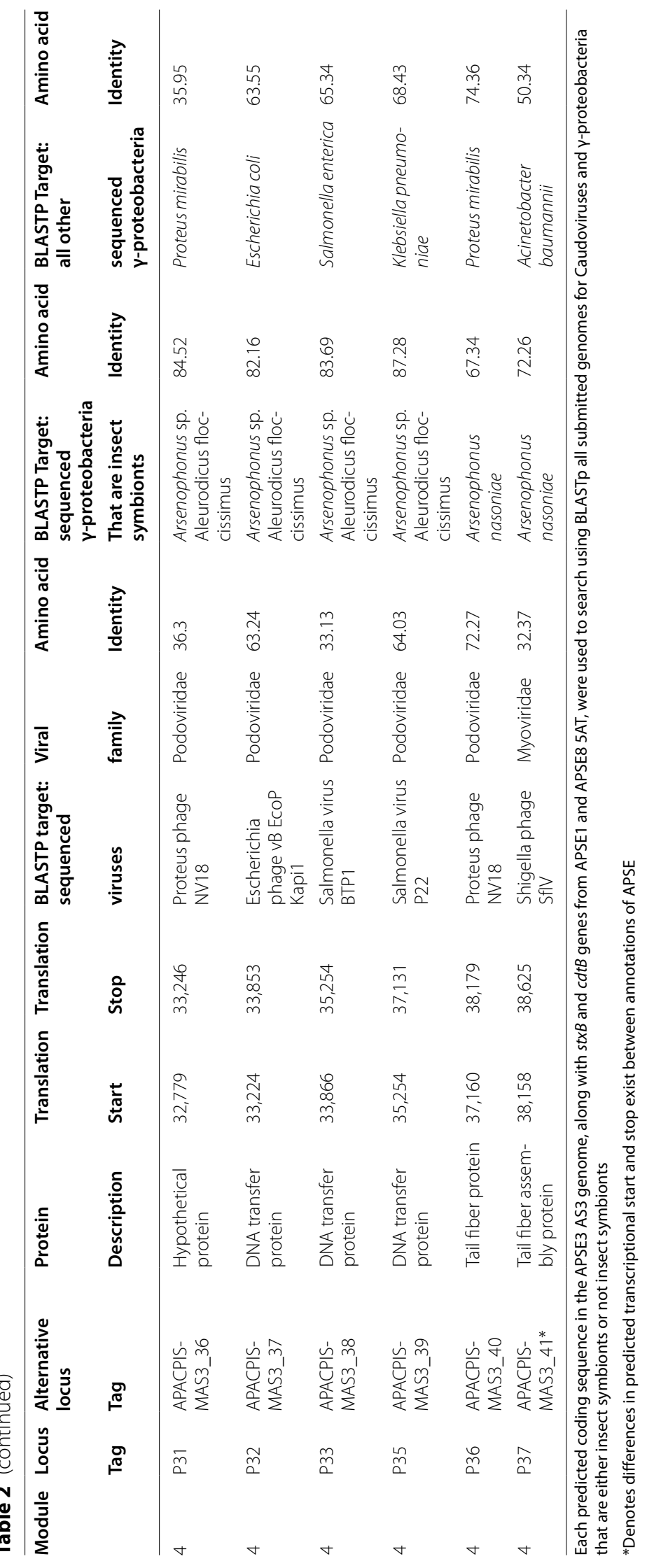




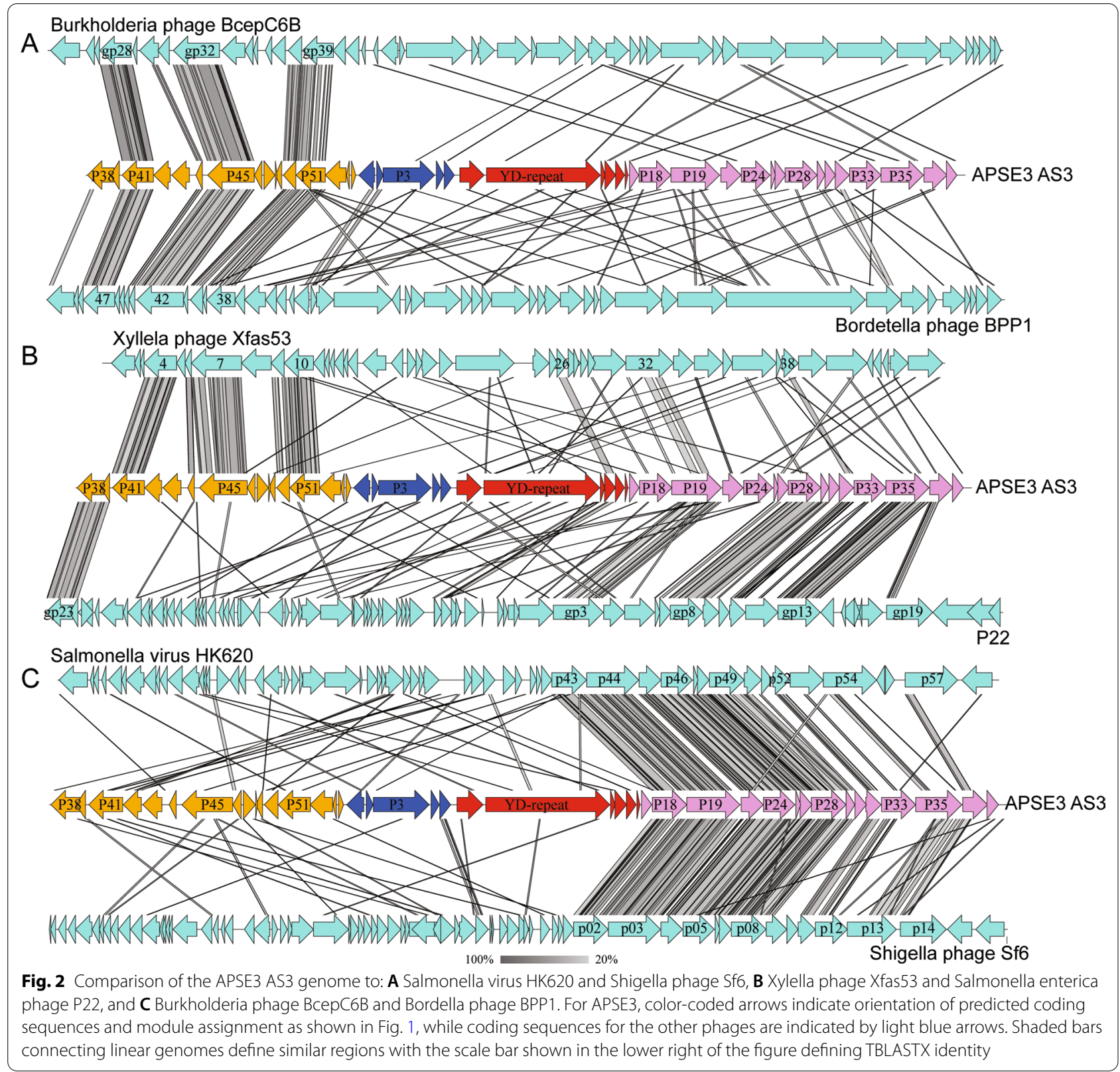

\section{Other Enterobacterales besides Arsenophonus spp. contain APSE-like genes}

We also assessed whether high identity homologs existed in any sequenced bacteria outside of $H$. defensa since this could suggest the presence of APSE-like prophages or prophage elements. We first considered other aphid symbionts, which like $H$. defensa, reside in the order Enterobacterales. These included several Arsenophonus spp. (Morganellaceae) and a Sodalis sp. (Pectobacteriaceae) that were already known to encode APSE-like genes [67, 72, 75]. We also included Buchnera and Pantoea (Erwiniaceae), Regiella and Fukatsuia that form a clade with $H$. defensa within the Yersiniaceae [30], and Serratia that is also in the Yersiniaceae. Best hits (25-96\% identities) using BLASTP were largely restricted to Arsenophonus spp., but included three genes from Sodalis glossinidius, Ca. Symbiopectobacterium, and Serratia symbiotica (Table 2). Extending this analysis to other Enterobacterales further identified high identity $(>60 \%)$ hits to APSE genes in four genera (Xenorhabdus, Morganella, Proteus, and Providencia) from the family Morganellaceae. Only four APSE genes $(p 19, p 23, p 27, p 28)$ shared $>60 \%$ identity outside of $\gamma$-Proteobacteria with best hits to each being to Mycobacterium tuberculosis (Actinomycetales). 
Given the preceding results, we interrogated the de novo genome assemblies available for four of the Arsenophonus spp., in which high identity APSE homologs were detected, from the perspective of both gene content and synteny. A single, small contig in Arsenophonus sp. str. ENCA contained a small syntenic region with coding sequences whose translation products shared high identities with products of the $p 3, p 4$ and $p 5$ genes in APSE module 2 (Additional file 1: Table S1; Fig. 3A). In Arsenophonus sp. ex. Aleurodicus floccissimus, one contig contained a colinear block consisting of $p 5, y d$ repeat and homologs of all genes in conserved order for APSE module 4 (p17-p37), while a single contig was identified in Arsenophonus sp. ex. Bemisia tabaci Asia II 3 that contained $p 5, c d t B$, and most genes $(p 17-p 28)$ in conserved order for APSE module 4 (Additional file 1: Table S1; Fig. 3B). We recognized that the assemblies for these Arsenophonus spp. could have captured only part of an APSE genome given each derives from short read data and cannot be fully assembled. We therefore asked if reanalysis could generate additional information. We could only access original data for A. nasoniae DSM15247 which consists of short reads generated by Wilkes et al. [74] plus recently generated long read data from $A$. nasoniae FIN (NCBI SRA SRS441142 and SRX301737). The new assembly we generated using these data, with APSE3 AS3 and APSE8 ZA17 as references, unambiguously identified two syntenic domains. The first consisted of most but not all genes in APSE modules 1 and 2 in conserved order plus $f$ (lysozyme) and $p 14$ in module 3 , while the second domain contained $p 14$ plus most genes in module $4(p 17-p 33)$ that were also in near fully conserved order (Fig. 3C). However, more than $1 \mathrm{Mb}$ of A. nasoniae DNA was present between these domains and the prophage element with extensive similarity to APSE modules 1 and 2 was associated with virion assembly genes not found in APSE. Reexamining the plasmid pSOG3 from S. glossinidius str. morsitans showed that six virion assembly genes (module 4 ) shared $>60 \%$ amino acid identities with corresponding APSE3 genes in module 4 (Additional file 1: Table S1; Fig. 3D). However, all other genes on this plasmid were unrelated to APSEs. The S. glossinidius str. morsitans main chromosome contained a second domain encoding genes that shared significant identities with predicted APSE proteins in modules 1-3 but gene order only weakly resembled an APSE due to the presence of several unrelated bacterial genes or viral genes from other phages (Additional file 1: Table S1; Fig. 3D).

Similar analysis of non-symbiont bacteria in the Morganellaceae detected homologs of APSE genes in colinear blocks corresponding to APSE module 1 and 2 plus a partial module 3 containing holin-lysozyme genes in the genomes of Morganella morganii (this region was associated with virion assembly genes not found in APSE) and two Providencia species (Additional file 1: Table S1; Fig. 4A). Colinear blocks corresponding to APSE module 4 were also identified in M. morganii, Proteus mirabilis, and two other Providencia species (Additional file 1: Table S1; Fig. 4B). In contrast, no colinear blocks or recognizable homologs were identified in these species that corresponded to APSE module 3 outside of $p 14$ and $p 16$. Close inspection of the three intact phages (MmP1, MP1, and MP2) that have been identified from $M$. morganii $[108,109]$, four intact phages (PM16, PM75, PM87, and PM93) that have been identified from Proteus mirabilis [110] and a single phage (PR1) identified from Providencia rettgeri [111] indicated that none shared genes or sequence homology with APSEs. A BLASTN search failed to find any additional phages that have been deposited into NCBI which contain APSE-like modules like those present in $M$. morganii.

Altogether, no fully intact APSE-like genomes were identified outside of $H$. defensa, but colinear blocks containing high identity genes in syntenic order that corresponded to APSE modules 1, 2 and 4 were in both Arsenophonus spp. that are insect symbionts and certain other species in the Morganellaceae that were not. However, the only bacterium outside of $H$. defensa that contained a largely intact APSE-like toxin domain (module 3) was Arsenophonus sp. ex. Aleurodicus floccissimus.

\section{Phylogenetic analyses}

Since phage elements with similar gene order in APSE modules 1 and 4 were identified in some symbiont and enteric species of Enterobacterales, we generated phylogenies using two module 1 genes, $p 41$ (helicase) and $p 45$ (DNApol), and two module 4 genes, $p 19$ (Portal protein) and $p 24$ (Major capsid protein). These genes were selected to capture phylogenetic signal from each module and represented genes for which we could easily obtain orthologs from other phage and bacterial genomes, hence providing phylogenetic signal. APSE MEAM and APSE MED exhibit structural mutations in $p 45$ that suggest

\footnotetext{
(See figure on next page.)

Fig. 3 Comparison of the APSE2 5AT or APSE3 AS3 genome to phage elements present in the genomes of: A Arsenophonus spp. endosymbiont in of Bemesia tabacii, B Arsenophonus endosymbiont in the whitefly Aleurodicus floccissimus, C Arsenophonus nasoniae present in the wasp Nasonia vitripennis, D Arsenophonus spp. ENCA and Arsenophonus triatominarum, and E Sodalis glossinidius. Predicted coding sequences and shaded bars connecting APSE genomes to identified phage elements are defined as described in Fig. 2. Annotations were not available for Arsenophonus triatominarum
} 


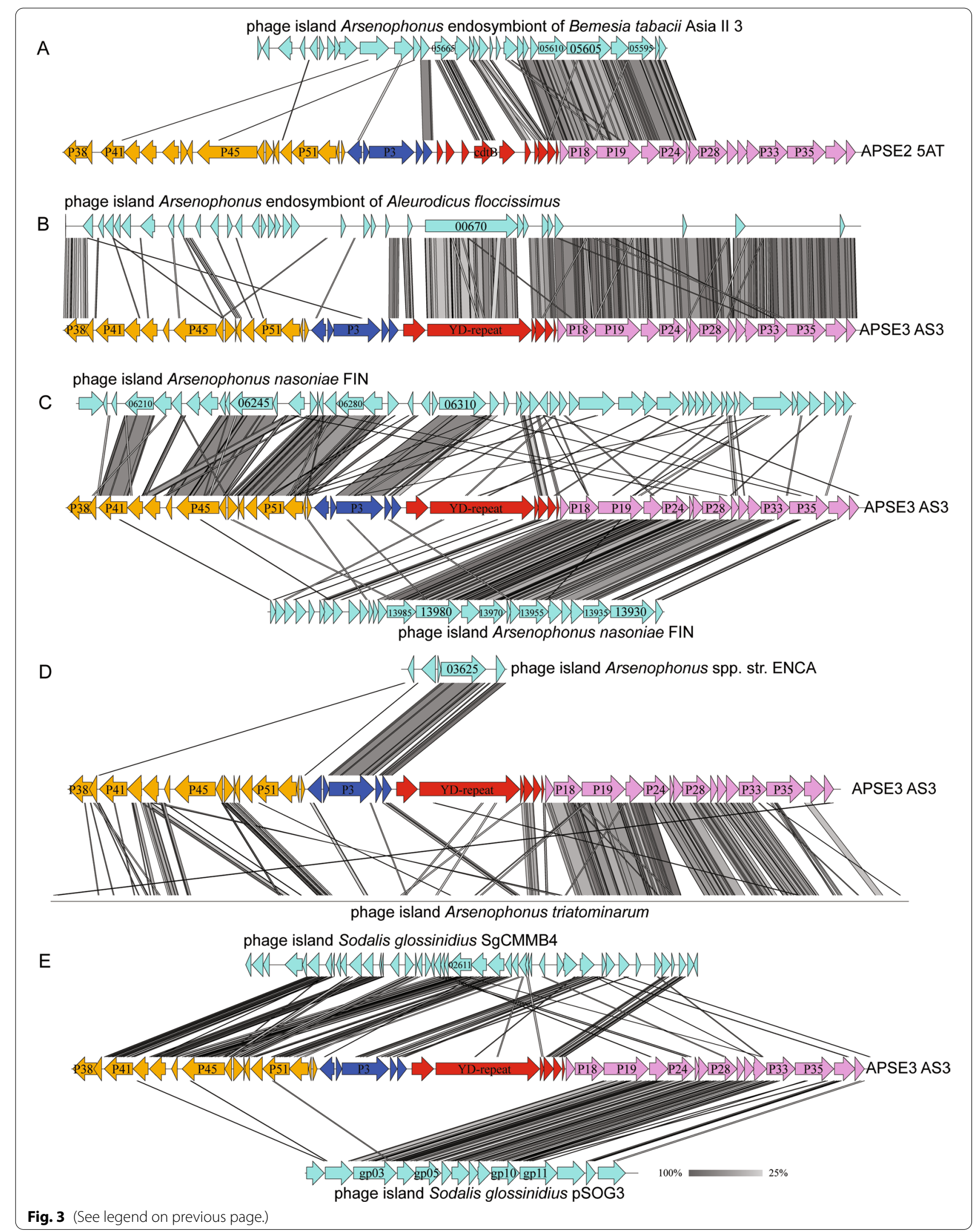




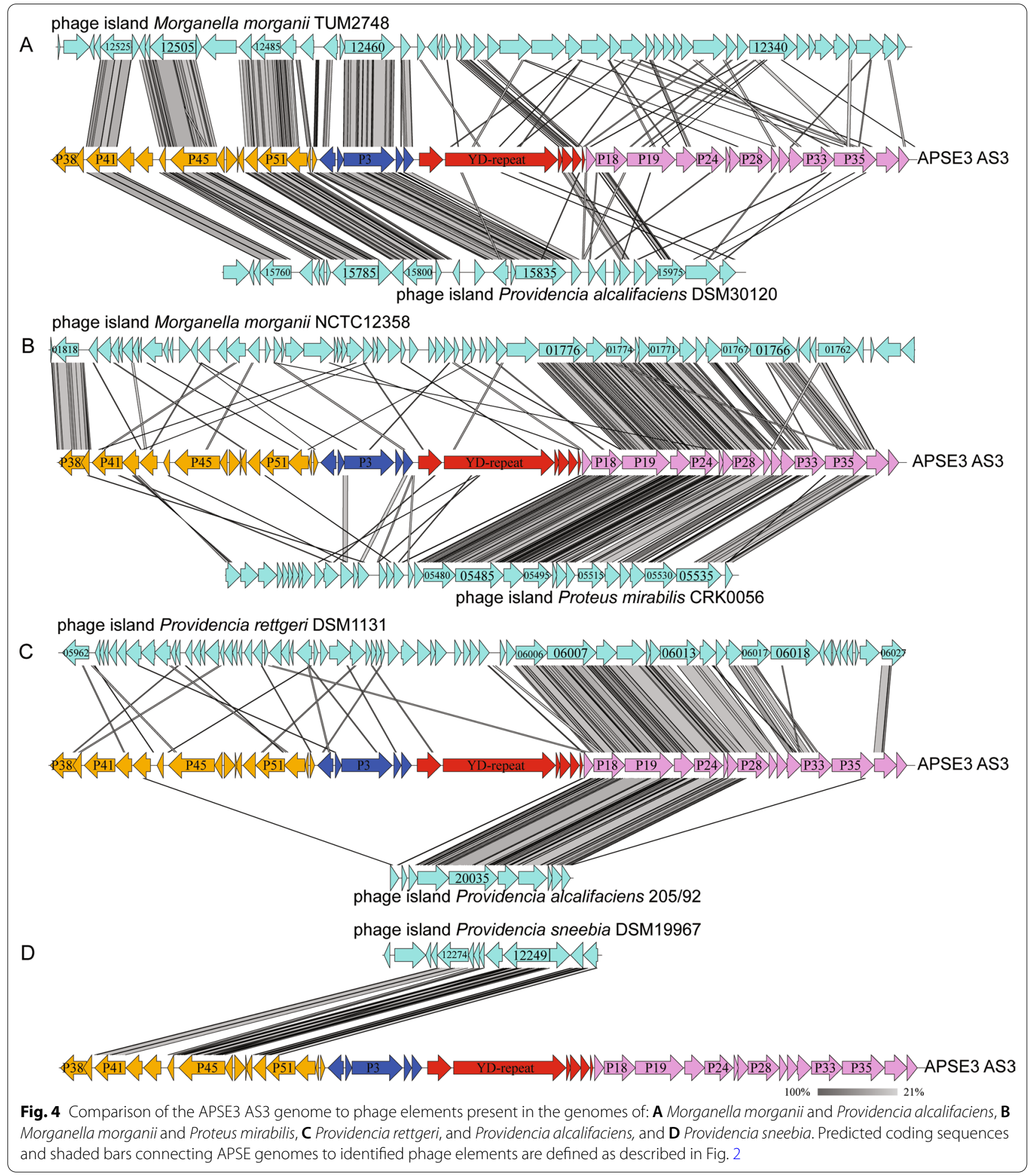

they are pseudogenized [38] while BLASTP identified frame shift mutations in $p 19$ from Arsenophonus sp. ex. Aleurodicus floccissimus. Phylogenetic trees further suggested inclusion of $p 45$ and $p 19$ pseudogenes generated phylogenetic error; namely long-branch attraction due to increased rates of nucleotide substitution in pseudogenes. We therefore conducted a phylogenetic analysis with pseudogenes removed. This analysis yielded several well-supported relationships (bootstrap support greater than 75\%). Using genes from module 1 indicated all APSE 
haplotypes from $H$. defensa form a clade that is sister to APSE-like elements in Arsenophonus spp., while genes from module 4 found a similar pattern with homologs from APSE and Arsenophonus spp. being sister to prophage elements in Morganella, Proteus, and Providencia spp. (Fig. 5). Given the possibility for recombination events generating false phylogenetic signals $[112,113]$, we constructed phylogenetic networks using the same genes, which also supported that APSEs from $H$. defensa were closest to Arsenophonus spp. (Additional file 1: Fig. S2).

As previously noted, gene content in module 3 differs among haplotypes with APSE1, 4 and 5 encoding stxB toxin subunit genes, APSE2 5AT, APSE2 NY26, APSE6, APSE7, APSE8 ZA17, APSE8 5D APSE MEAM, and APSE MED encoding $c d t B$ toxin subunit genes, and APSE3 AS3 encoding a $y d$ repeat toxin gene [38, 51, 55]. We asked if $c d t B$ represents a plesiomorphy within APSE phages. If $c d t B$ diverged with APSE strains, we would expect the sequences in APSE2 5AT, APSE2 NY26 and APSE8 ZA17, APSE8 5D to share a similar number of identical DNA bases as APSE MEAM and APSE MED when compared to $c d t B$ in, for example, Arsenophonus spp. ex Bemisa tabaci (in this case $c d t B$ is a true homolog). However, if a $c d t B$ moved by horizontal transfer from APSEs that infect $H$. defensa to the APSE-like phage element in Arsenophonus spp. ex Bemisa tabaci (or vice versa), then we would expect one of the $c d t B$ genes in APSEs from H. defensa to be more similar to the Arsenophonus based $c d t B$ gene (a paralog). We would further predict that $c d t B$ in APSE MEAM/MED would also be more similar to the APSE-like $c d t B$ gene in Arsenophonus spp. ex Bemisa tabaci given each infects the same whitefly host as $H$. defensa strains MEAM and MED. Results indicated that the percentage of shared identical nucleotides between $c d t B$ in the phage element in Arsenophonus spp. ex. Bemisia tabaci Asia II 3 and APSEs were similar for both APSE MEAM/MED (46.1\%) and APSE2/8 $(47.7 \%)$, which was consistent with the $c d t B$ genes representing a plesiomorphy in APSE (fig. S3).

\section{Discussion}

The first studies of APSE genomes emphasized the variable content of virulence genes and their potential importance in converting $H$. defensa into a selective parasitoid pathogen $[36,55,59,62]$. More recently, comparative data have identified other variable regions in APSE genomes while also showing that certain species of Arsenophonus contain APSE-like genes [67]. Results presented in this study further contribute to the APSE literature by showing that multiple haplotypes are organized into two functional units and four modules, with module order and gene order within modules 1, 2 and 4 being conserved. Our results also indicate that APSEs integrate into a conserved domain of the $H$. defensa genome while certain other phages and phage elements contain blocks of genes that share syntenic order with APSE modules 1, 2 and 4 . While gene order and content of module 3 has previously been shown to differ among haplotypes [55, 67], our full genome comparison indicates the location of module 3 is located immediately downstream of the anti-termination protein Q gene ( $p 5)$. This location is likely important, because virulence gene-containing modules in several other tailed phages that lysogenically convert host bacteria into pathogens are located in the same position $[60,113]$. Genomic data for three $H$. defensa containing proviral APSEs that infect aphids in the genera Cinara, Drepanosiphum, and Eriosoma were also recently generated by short read sequencing [67]. We did not include these proviral APSEs in our formal analysis but inspection of these genomes indicates that gene order within modules 1, 2 and 4 are fully consistent with the APSE haplotypes that we analyzed.

Our results indicate that gene content and order of APSE module 4 is very similar to the virion assemble module of P22-like podoviruses [68, 70] while module 1 plus $p 1$ and $p 2$ (module 2) share syntenic order and identity with non-P22 like podoviruses that infect Bordetella spp. (BPP-1, BIP-1, BMP-1), Burkholderia spp. (Bcep complex), Xylella fastidiosa, and Yersinia enterocolitica phage YeP4 [106, 107]. Thus, APSEs have mosaic genomes that consist of early Bordetella-Bcep-X. fastidiosa-like genes (module 1,2) and late P22-like genes (module 4) with a centrally located toxin-holin-lysozyme domain (module 3) that shares no significant identity with other fully sequenced phages. APSE-like phages thus could have arisen through either module exchange between phages that infect disparate hosts or from a related phage with a similarly organized genome that has not been identified. The APSE-like domains in the genomes of Arsenophonus spp. were previously reported to not be intact [67], the results presented in this study indicate they contain syntenic regions that correspond to all of the APSE modules. That syntenic domains exist in

(See figure on next page.)

Fig. 5 Maximum-likelihood phylograms depicting evolutionary relationships for two genes in module 1 ( $p 41$ and $p 45$ ) and two genes in module 4 (p19 and p24) of APSEs, other phages and other phage elements from bacteria in the order Enterobacteriales. Numbers at nodes indicate percent of 1000 bootstrap replicates that recovered the same node. For each gene, tip labels indicate the APSE haplotype, sequenced phage, or bacterium containing a prophage element in which the ortholog resided. Scale bars indicates nucleotide substitutions per site. Tick marks indicate branches lengths at the root have been reduced 


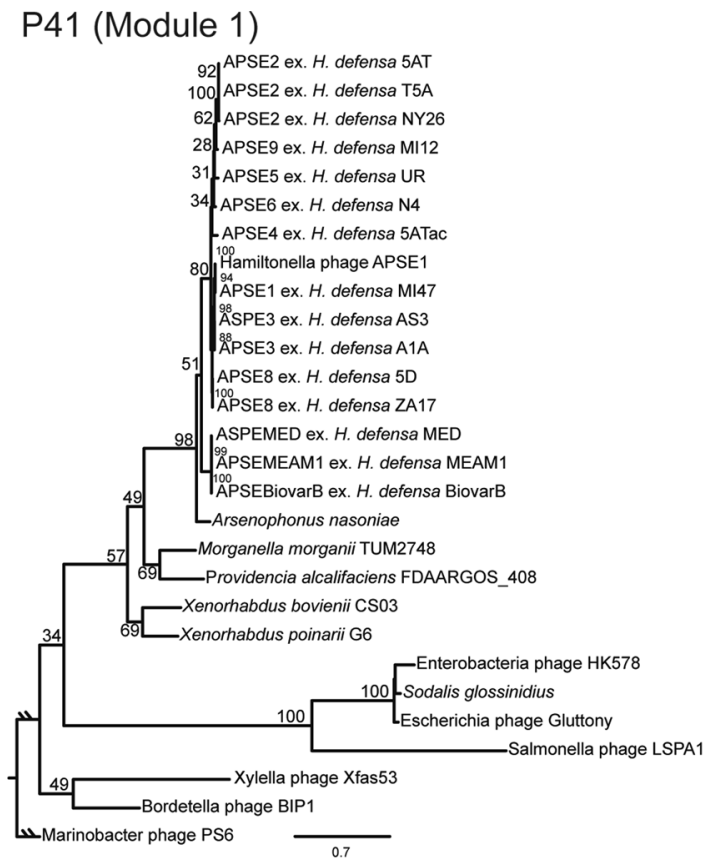

P19 (Module 4)

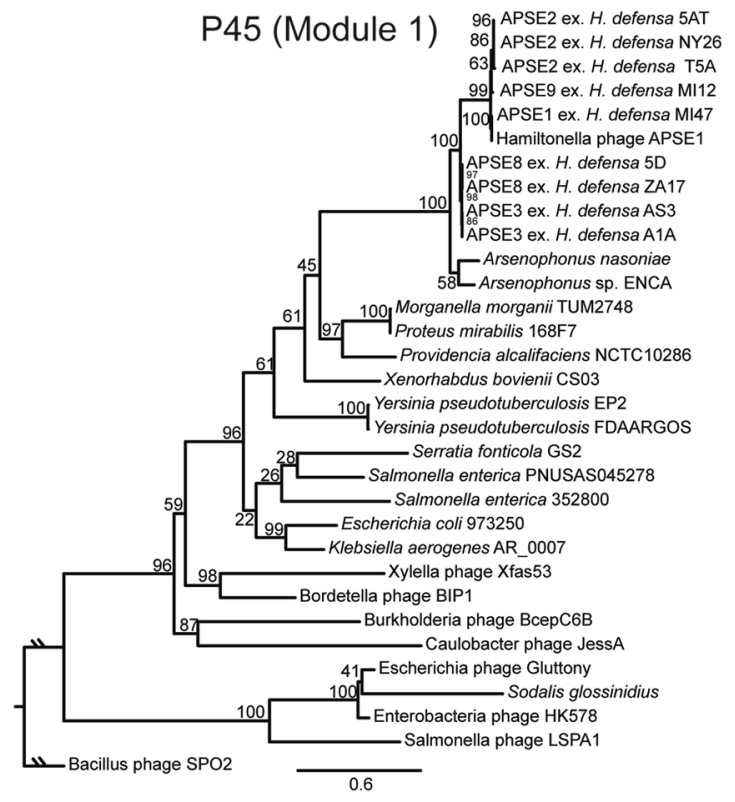

P24 (Module 4)

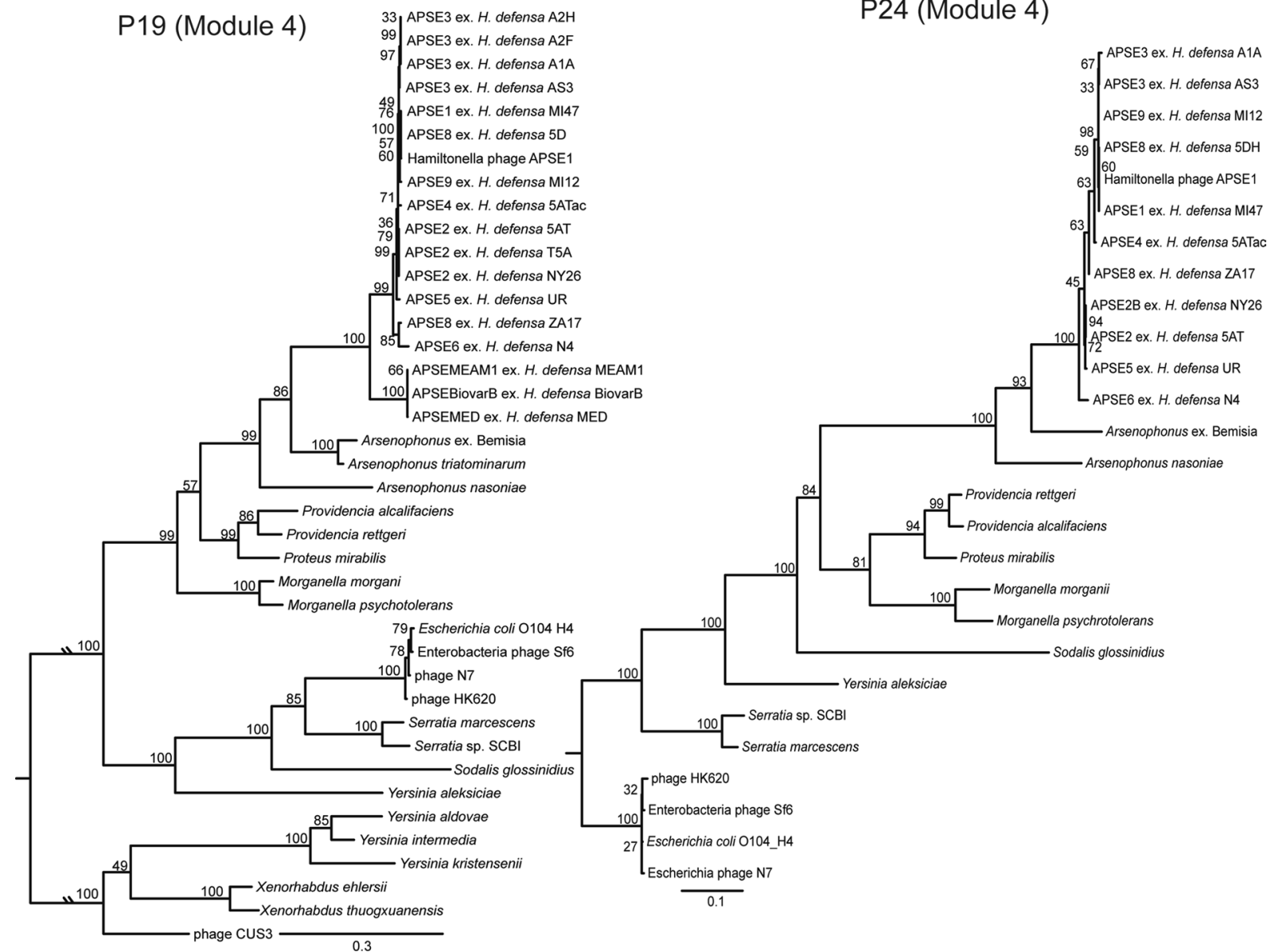

Fig. 5 (See legend on previous page.) 
several other species in the Morganellaceae further suggest APSE-like phages may infect bacteria that are not insect symbionts.

Our results support a close relationship between APSE and prophage elements in Arsenophonus spp., but cannot answer whether they represent related but independently acquired viruses or are evidence that host shifts have occurred between $H$. defensa and Arsenophonus symbionts. If we are correct that the $c t d B$ genes in APSEs and APSE-like elements are orthologs, it is possible that the $c t d B$ gene represents an ancestral state, that $y d$ repeat and $s t x B$ genes represent replacements of the $c d t B$ gene and that exchange of APSE or APSE-like phage between $H$. defensa and Arsenophonus has occurred since the acquisition of novel toxin genes. It is also possible that ancestral APSE-like phages contained different toxin genes, prior to the existence of modern $H$. defensa, and that multiple acquisition events have occurred, moving multiple toxin genes into $H$. defensa. Alternatively, our preferential detection of APSE-like prophage elements in Arsenophonus and certain other genera could reflect biases in the species of bacteria that have been sequenced to date. That APSE-like phages may infect bacteria in the Enterobacterales more broadly is supported by the detection of APSE-like elements during this study and previously [9] in S. glossinidius str. morsitans (Pectobacteriaceae) although weak synteny in gene order and overall low gene identities indicate severe decay of the ancestral APSE-like genome in this host species.

A limitation of using phylogenetic methods in discerning relationships of phage, is that recombination can obscure phylogenetic signal or create false relationships. One way in which this may be evident is disagreement between gene trees (i.e. gene tree-species tree conflict). In this study we selected two genes from the two larger modules, which had affinities to certain phage groups. This allowed us conduct phylogenetic analysis using identifiable orthologs shared between APSE and other genomes; however, we recognize that other gene trees could support an alternative arrangement, particularly when comparing between modules.

\section{Conclusions}

APSEs have mosaic genomes that are organized into two functional units and four modules. Module order is conserved among haplotypes and the position of module 3 , which encodes virulence factors, is likely important in converting $H$. defensa into a protective symbiont. APSE modules 1, 2 and 4 encode regulatory and structural genes, and these modules share syntenic domains with other phages and phage elements associated with symbiotic and non-symbiotic bacteria. We conclude that APSE arose through module exchange among phages, presently characterized or not, with similarly organized genomes.

\begin{abstract}
Abbreviations
AIC: Akaike information criterion; APSE: Acyrthosiphon pisum Secondary endosymbiont; BLAST: Basic local alignment search tool; bp: Base pairs; cdtB: Cytolethal distending toxin encoding gene; DNA: Deoxyribonucleic acid; DNApol: DNA polymerase; ds: Double stranded; GTR: General time reversable model of nucleotide substitution; NCBI: National Center for Biotechnology Information; nr: Non-redundant; stxB: Shiga toxin encoding gene; tRNA: Transfer ribonucleic acid; Arg: Arginine.
\end{abstract}

\section{Supplementary Information}

The online version contains supplementary material available at https://doi. org/10.1186/s12985-021-01685-y.

Additional file 1. Supplementary figures and table.

\section{Acknowledgements}

We thank Gaelen R Burke, Alejandro Manzano Marín, and an anonymous reviewer for comments and suggestions on the manuscript. High Performance Computing resources provided by the High Performance Research Computing (HPRC) Core Facility at Virginia Commonwealth University (https:// chipc.vcu.edu) were used for conducting the research reported in this work.

\section{Authors' contributions}

MRS, KMO, GC, and BMB designed the study, VP, GC, and BMB identified prophage, $\mathrm{GC}$ and $\mathrm{BMB}$ conducted comparative genomics, BMB conducted phylogenetic analysis, and all authors contributed to the preparation and editing of the manuscript. All authors read and approved the final manuscript.

\section{Funding}

This work was supported by Grants from the US National Science Foundation award (IOS 1256794 to K.M.O. and M.R.S.), USDA Hatch program (GEO00772 to M.R.S), and the Virginia Commonwealth University.

\section{Availability of data and materials}

Nucleotide alignments, phylogenetic trees, and prophage assembly from Arsenophonus nasoniae have been deposited in figshare https://doi.org/10.6084/ m9.figshare.14744397. Genome assemblies of Hamiltonella defensa including proviral elements were obtained from NCBI https://www.ncbi.nlm.nih.gov/ and include CP017605-CP017610, CP022932-CP022937, СP021663-CP021665, and CP023987-CP023990. Raw sequencing data used in the assemblies of APSE genomes are available on NCBI and include SRR15674828-SRR15674831, SRR15676030, SRR1585572, and SRR15691200.

\section{Declarations}

Ethics approval and consent to participate

Ethics approval was not required to conduct this work.

Consent for publication

The authors provide BMC Virology Journal consent to publish this manuscript.

Competing interests

The authors declare that they have no competing interests.

Author details

${ }^{1}$ Department of Entomology, University of Georgia Athens, Athens, GA, USA. ${ }^{2}$ Present Address: Center for Biological Data Science, Virginia Commonwealth University, Richmond, VA, USA. ${ }^{3}$ Laboratoire de Génétique et Pathologie des Mollusques Marins, IFREMER, La Tremblade, France. 
Received: 17 February 2021 Accepted: 1 November 2021

Published online: 10 November 2021

\section{References}

1. Rohwer F. Global phage diversity. Cell. 2003;113:141.

2. Weinbauer MG. Ecology of prokaryotic viruses. FEMS Microbiol Rev. 2004;28:127-81.

3. Rohwer F, Barott K. Viral information. Biol Philos. 2013;28:283-97.

4. Suttle CA. Marine viruses-major players in the global ecosystem. Nat Rev Microbiol. 2007;5:801-12.

5. Brussaard CP, Wilhelm SW, Thingstad F, Weinbauer MG, Bratbak G, Heldal M, Kimmance SA, Middelboe M, Nagasaki K, Paul JH, Schroeder DC, Suttle CA, Vaqué D, Wommack KE. Global-scale processes with a nanoscale drive: the role of marine viruses. ISME J. 2008;2:575-8.

6. Fortier LC, Sekulovic O. Importance of prophages to evolution and virulence of bacterial pathogens. Virulence. 2013:4:354-65.

7. Keen EC, Bliskovsky VV, Malagon F, Baker JD, Prince JS, Klaus JS, Adhya SL. Novel 'Superspreader' bacteriophages promote horizontal gene transfer by transformation. MBio. 2017;8:e02115-e2116

8. van der Wilk F, Dullemans AM, Verbeek $M$, van den Heuvel FJM. Isolation and characterization of APSE-1, a bacteriophage infecting the secondary endosymbiont of Acrythosiphon pisum. Virology. 1999;262:104-13.

9. Clark AJ, Pontes M, Jones T, Dale C. A possible heterodimeric prophagelike element in the genome of the insect endosymbiont Sodalis glossinidius. J Bacteriol. 2007;189:2949-51.

10. Moran NA, McCutcheon JP, Nakabachi A. Genomics and evolution of heritable bacterial symbionts. Annu Rev Genet. 2008;42:165-90.

11. Tanaka K, Furukawa S, Nikoh N, Sasaki T, Fukatsu T. Complete WO phage sequences reveal their dynamic evolutionary trajectories and putative functional elements required for integration into the Wolbachia genome. Appl Environ Microbiol. 2009;75:5676-86.

12. Mclean AHC, Godfray HCJ. Evidence for specificity in symbiont-conferred protection against parasitoids. Proc Biol Sci. 2015. https://doi.org/ 10.1098/rspb.2015.0977.

13. Pramono AK, Kuwahara H, Itoh T, Toyoda A, Yamada A, Hongoh Y. Discovery and complete genome sequence of a bacteriophage from an obligate intracellular symbiont of cellulolytic protest in the termite gut. Microbes Environ. 2017:32:112-7.

14. Leigh BA, Bordenstein SR, Brooks AW, Mikaelyan A, Bordenstein SR. Finer-scale phylosymbiosis: insights from insect viromes. mSystems. 2018;3:e00131-18.

15. Buchner P. Endosymbiosis of animals with plant microorganisms. New York: Interscience; 1965.

16. Puchta O. Experimentelle untersuchungen uber die bedeutung der symbiose der kliderlaus Pediculus vestimenti Brum. Z Parasitenkd. 1955;17:1.

17. Douglas AE. Sulphate utilization in an aphid symbiosis. Insect Biochem. 1988;28:599-605

18. Oliver KM, Russell JA, Moran NA, Hunter MS. Facultative bacterial symbionts in aphids confer resistance to parasitic wasps. Proc Natl Acad Sci USA. 2003:100:1803-7.

19. Kaltenpoth M, Göttler W, Herzner G, Strohm E. Symbiotic bacteria protect wasp larvae from fungal infestation. Curr Biol. 2005:15:475-9.

20. Scarborough CL, Ferrari J, Godfray HC. Aphid protected from pathogen by endosymbiont. Science. 2005:310:1781.

21. Oliver KM, Campos J, Moran NA, Hunter MS. Population dynamics of the defensive symbionts in aphids. Proc R Soc B. 2007;275:293-9.

22. Hedges LM, Brownlie JC, O'Neill SL, Johnson KN. Wolbachia and virus protection in insects. Science. 2008;322:702.

23. Douglas AE. The microbial dimension in insect nutritional ecology. Funct Ecol. 2009;23:38-47.

24. Jaenike J. Population genetics of beneficial heritable symbionts. Trends Ecol Evol. 2012;27:226-32

25. Bressan A. Emergence and evolution of Arsenophonus bacteria as insect-vectored plant pathogens. Infect Genet Evol. 2014;22:81-90.

26. Nikoh N, Hosokawa T, Moriyama M, Oshima K, Fukatsu T. Evolutionary origins of insect-Wolbachia nutritional mutualism. Proc Natl Acad Sci USA. 2014:111:10257-62.
27. Tsuchida T, Koga R, Horikawa M, Tsunoda T, Maoka T, Matsumoto S, Simon JC, Fukatsu T. Symbiotic bacterium modifies aphid body color. Science. 2010;330:1102-4.

28. Nakabachi A, Ueoka R, Oshima K, Teta R, Mangoni A, Gurgui M. Defensive bacteriome symbiont with a drastically reduced genome. Curr Biol. 2013;23:1478-84.

29. Heyworth ER, Ferrari J. Heat stress affects facultative symbiont-mediated protection from a parasitoid wasp. PLoS ONE. 2016;11:e0167180.

30. Patel V, Chevignon G, Manzano-Marín A, Brandt JW, Strand MR, Russell JA, Oliver KM. Cultivation-assisted genome of Candidatus Fukatsuia symbiotica; the enigmatic 'X-type' symbiont of aphids. Genome Biol Evol. 2019:11:3510-22.

31. Oliver KM, Degnan PH, Burke GR, Moran NA. Facultative symbionts in aphids and the horizontal transfer of ecologically important traits. Rev Entomol. 2010;55:247-66.

32. Oliver KM, Martinez AJ. How resident microbes modulate ecologicallyimportant traits of insects. Curr Opin Insect Sci. 2014;4:1-7.

33. Douglas AE. Nutritional interaction in insect-microbial symbioses: aphids and their symbiotic bacteria Buchnera. Annu Rev Entomol. 1998;43:17-37.

34. Zchori-Fein E, Brown JK. Diversity of prokaryotes associated with Bemisia tabaci (Gennadius) (Hemiptera: Aleyrodidae). Ann Entomol Soc Am. 2012;95:711-8.

35. Russell JA, Latorre A, Sabater-Munoz B, Moya A, Moran NA. Side-stepping secondary symbionts: widespread horizontal transfer across and beyond the Aphidoidea. Mol Ecol. 2004;124:1061-75.

36. Moran NA, Degnan PH, Santos SR, Dunbar HE, Ochman H. The players in a mutualistic symbiosis: insects, bacteria, viruses and virulence genes. Proc Natl Acad Sci USA. 2005;102:16919-26.

37. Henry LM, Maiden MCJ, Ferrari J, Godfray HCJ. Insect life history and the evolution of bacterial mutualism. Ecol Lett. 2015;186:516-25.

38. Rollat-Farnier PA, Santos-Garcia D, Rao Q, Sagot MF, Silva FJ, Henri H, et al. Two host clades, two bacterial arsenals: evolution through gene losses in facultative endosymbionts. Genome Biol Evol. 2015;7:839-55.

39. Zytynska SE, Weisser WW. The natural occurrence of secondary bacterial symbionts in aphids. Ecol Entomol. 2015;411:13-26.

40. Brandt JW, Chevignon G, Oliver KM, Strand MR. Culture of an aphid heritable symbiont demonstrates its direct role in defence against parasitoids. Proc R Soc B. 2017;284:2017925.

41. Oliver KM, Higashi CHV. Variations on a protective theme: Hamiltonella defensa infections in aphids variably impact parasitoid success. Curr Opin Insect Sci. 2019:32:1-7.

42. Vorburger C, Sandrock C, Gouskov A, Castaneda LE, Ferrari J. Genotypic variation and the role of defensive endosymbionts in all-parthenogenetic host-parasitoid interaction. Evolution. 2009;63:1439-50.

43. Schmid M, Sieger R, Zimmermann YS, Vorburger C. Development, specificity and sublethal effects of symbiont-conferred resistance to parasitoids in aphids. Funct Ecol. 2012;261:207-15.

44. Asplen MK, Bano N, Brady CM, Desneux N, Hopper KR, Malouines C, et al. Specialisation of bacterial endosymbionts that protect aphids from parasitoids. Ecol Entomol. 2014;39:736-9.

45. Martinez AJ, Kim KL, Harmon JP, Oliver KM. Specificity of multimodal aphid defenses against two rival parasitoids. PLOS ONE. 2016;11:e0154670.

46. Oliver KM, Moran NA, Hunter MS. Variation in resistance to parasitism in aphids is due to symbiont not host genotype. Proc Natl Acad Sci USA 2005; 102:12795-800

47. Martinez AJ, Weldon SR, Oliver KM. Effects of parasitism on aphid nutritional and protective symbioses. Mol Ecol. 2014;23:1594-607.

48. Oliver KM, Smith AH, Russell JA. Defensive symbiosis in the real worldadvancing ecological studies of heritable, protective bacteria in aphids and beyond. Funct Ecol. 2014:23:1594-607.

49. Cayetano L, Vorburger C. Symbiont-conferred protection against Hymenopteran parasitoids in aphids: how general is it? Ecol Entomol. 2015;40:85-93.

50. Sandstrom JP, Russel JA, White JP, Moran NA. Independent origins and horizontal transfer of bacterial symbionts of aphids. Mol Ecol. 2001;101:217-28.

51. Rao Q, Rollat-Farnier PA, Zhu DT, Santos-Garcia D, Silva F, Moya A, et al. Genome reduction and potential metabolic complementation of 
the dual endosymbionts the whitefly Bemesia tabaci. BMC Genom. 2015;16:226.

52. Martinez AJ, Doremus MR, Kraft LJ, Kim KL, Oliver KM. Multi-modal defences in aphids offer redundant protection and increased costs likely impeding a protective mutualism. J Anim Ecol. 2017;87:464-77.

53. Dennis AB, Patel V, Oliver KM, Vorburger C. Parasitoid gene expression changes after adaptation to symbiont-protected hosts. Evolution. 2017;71:2599-617.

54. Hopper KR, Kuhn KL, Lanier K, Rhoads JH, Oliver KM, White KM, et al. The defensive aphid symbiont Hamiltonella defensa affects host quality differently for Aphelinus glycinis versus Aphelinus atriplicis. Biol Cont. 2017:116:3-9.

55. Degnan PH, Moran NA. Diverse phage-encoded toxins in a protective insect endosymbiont. Appl Environ Microbiol. 2008;74:67826791.

56. Chevignon G, Boyd BM, Brandt JW, Oliver KM, Stand MR. Culture-facilitated comparative genomics of the facultative symbiont Hamiltonella defensa. Genome Biol Evol. 2018;10:786-802.

57. Oliver KM, Degnan PH, Hunter MS, Moran NA. Bacteriophages encode factors required for protection in symbiotic mutualism. Science. 2009;325:992-4.

58. Weldon SR, Strand MR, Oliver KM. Phage loss and the breakdown of a defensive symbiosis in aphids. Proc R Soc Lond B. 2013;1751:2012-103.

59. Degnan PH, Yu Y, Sisneros N, Wing RA, Moran NA. Hamiltonella defensa, genome evolution of a protective bacterial endosymbiont from pathogenic ancestors. Proc Natl Acad Sci USA. 2009;106:9063-8.

60. Brussow H, Canchaya C. Hardt W-D. Phages and the evolution of bacterial pathogens: from genomic rearrangements to lysogenic conversion. Microbiol Mol Biol Rev. 2004;68:560-602.

61. Lynn-Bell NL, Strand MR, Oliver KM. Bacteriophage acquisition restores protective mutualism. Microbiology. 2019;165:985-9.

62. Degnan PH, Moran NA. Evolutionary genetics of a defensive facultative symbiont of insects: exchange of toxin-encoding bacteriophage. Mol Ecol. 2008;2008(17):916-29.

63. Oliver KM, Campos J, Moran NA, Hunter MS. Population dynamics of defensive symbionts in aphids. Proc Roy Soc B. 2008:275:293-9.

64. Gehrer $L$, Vorburger C. Parasitoids as vectors of facultative bacterial endosymbionts in aphids. Biol Letters. 2012;8:613-5.

65. Henry LM, Peddoud J, Simon JC, Hadfield JD, Maiden MJC, Ferrari J, Godfray HCJ. Horizontally transmitted symbionts and host colonization of ecological niches. Curr Biol. 2013;2317:1713-7.

66. Li Q, Fan J, Sun J, Wang M-Q, Chen J. Plant-mediated horizontal transmission of Hamiltonella defensa in the wheat aphid Sitobion miscanthi. J Agric Food Chem. 2018;66:13367-77.

67. Rouïl J, Jousselin E, Coeur d'acier A, Cruaud C, Manzano-Marin A. The protector within: comparative genomics of APSE phage across aphids reveals rampant recombination and diverse toxin arsenals. Genome Biol Evol. 2020;12:878-89.

68. Casjens SR, Thuman-Commike PA. Evolution of mosaically related tailed bacteriophage genomes seen through the lens of phage P22 virion assembly. Virology. 2011;15:393-415.

69. Casjens SR, Grose JH. Contributions of P2- and P22-like prophages to understanding the enormous diversity and abundance of tailed bacteriophages. Virology. 2016:496:255-76.

70. Grose JH, Casjens SR. Understanding the enormous diversity of bacteriophages: the tailed phages that infect the bacterial family Enterobacteriaceae. Virology. 2014;468-470:421-43.

71. Clark AJ, Inwood W, Cloutier T, Dhillon TS. Nucleotide sequence of coliphage HK620 and the evolution of lambdoid phages. J Mol Biol. 2001:311:657-79.

72. Hansen AK, Jeong G, Paine TD, Stouthamer R. Frequency of secondary symbiont infection in an invasive psyllid related to parasitism pressure on a geographic scale in California. Appl Environ Microbiol. 2007;73:7531-5.

73. Tay Taylor GP, Coghlin PC, Floate KD. Perlman SJ. The host range of the male-killing symbiont Arsenophonus nasoniae in filth fly parasitoids. J Invertebr Pathol. 2011;106:371-9.

74. Wilkes TE, Darby AC, Choi JH, Colboume JK, Werren JH, Hurst GD. The draft genome sequence of Arsenophonus nasoniae, son-killer bacterium of Nasonia vitripennis, reveals genes associated with virulence and symbiosis. Insect Mol Biol. 2010;19(Suppl 1):59-73.
75. Duron O. Arsenophonus insect symbionts are commonly infected with APSE, a bacteriophage involved in protective symbiosis. FEMS Microbiol Ecol. 2014:90:184-94.

76. Katoh K, Standley DM. MAFFT multiple sequence alignment software version 7: improvements in performance and usability. Mol Biol Evol. 2013;30:772-80

77. Kearse M, Moir R, Wilson A, Stones-Havas S, Cheung M, Sturrock S, et al. Geneious basic: an integrated and extendable desktop software platform for the organization and analysis of sequence data. Bioinformatics. 2012;3812:1647-9.

78. Chen W, Hasegawa DK, Kaur N, Kliot A, Pinheiro PV, Luan J, et al. The draft genome of whitefly Bemisia tabaci MEAM1, a global crop pest, provides novel insights into virus transmission, host adaptation, and insecticide resistance. BMC Biol. 2016;14:110.

79. Langmead B, Slazberg SL. Fast gapped-read alignment with Bowtie. Nat Methods. 2013;2(9):357-9.

80. Altschul SF, Gish W, Miller W, Myers EW, Lipman DJ. Basic local alignment search tool. J Mol Biol. 1990;1990(215):403-10.

81. Alikhan NF, Petty NK, Ben Zakour NL, Beastson SA. BLAST ring image generator (BRIG): simple prokaryote genome comparison. BMC Genom. 2011;12:402.

82. Sullivan MJ, Petty NK, Beatson SA. Easyfig: a genome comparison visualizer. Bioinformatics. 2011;27:1009-10.

83. Marchler-Bauer A, Bryant SH. CD-search: protein domain annotations on the fly. Nucleic Acids Res. 2004;32:327-31.

84. Allen JM, Huan DI, Cronk QC, Johnson KP. aTRAM-automated target restricted assembly method: a fast method assembling loci across divergent taxa from next-generation sequencing data. BMC Bioniform. 2015;16:98.

85. Allen JM, Boyd MB, Nguyen NP, Vachaspati P, Warnow T, Huang DI, et al. Phylogenomics from whole genome sequences using aTRAM. Syst Biol. 2017;66:786-98.

86. Boyd BM, Allen JM, Nguyen NP, Vachaspati P, Quicksall ZS, Warnow T, et al. Primates, lice and bacteria: speciation and genome evolution in the symbionts of hominid lice. Mol Biol Evol. 2017;34:1743-57.

87. Stamatakis A. RAxML version 8: a tool for phylogenetic analysis and post-analysis of large phylogenies. Bioinformatics. 2014;30:1312-3.

88. Lanfear R, Frandsen PB, Wright AM, Senfeld T, Calcott B. PartionFinder2: new methods for selecting partitioned models of evolution for molecular and morphological phylogenetic analyses. Mol Biol Evol. 2017;34:772-3.

89. Bryant $D$, Moulton V. NeighborNet: an agglomerative algorithm for the construction of planar phylogenetic networks. Mol Biol Evol. 2004;21:255-65.

90. Huson DH, Bryant D. Application of phylogenetic networks in evolutionary studies. Mol Biol Evol. 2006;23:254-67.

91. Casjens S. Diversity among the tailed-bacteriophages that infect the Enterobacteriaceae. Res Microbiol. 2008;159:340-8.

92. Botstein D, Herskowitz I. Properties of hybrids between Salmonella phage P22 and coliphage lambda. Nature. 1974;251:584-9.

93. Boyd EF, Brussow H. Common themes among bacteriophage-encoded virulence factors and diversity among the bacteriophages involved. Trends Microbiol. 2002:10:521-9.

94. Gamage SD, Strasser JE, Chalk CL, Weiss AA. Nonpathogenic Escherichia coli can contribute to the production of Shiga toxin. Infect Immun. 2003;71:3107-3015.

95. Susskind MM, Botstein D. Molecular genetics of bacteriophage P22. Microbiol Rev. 1978;42:385-413.

96. Botstein D. A theory of modular evolution for bacteriophage. Ann NY Acad Sci. 1980:354:484-90.

97. Hendrix RW, Smith MCM, Burns RN, Ford ME, Hatfull GF. Evolutionary relationships among diverse bacteriophages and prophages: all the world's a phage. Proc Natl Acad Sci USA. 1999;96:2192-7.

98. Juhala RJ, For ME, Duda RL, Youlton A, Hatfull GF, Hendrix RW. Genomic sequences of bacteriophages HK97 and HK022: pervasive genetic mosaicism in the lamboid bacteriophages. J Mol Biol. 2000;299:27-51.

99. Brussow H, Hendrix RW. Phage genomics: small is beautiful. Cell. 2002:108:13-6.

100. Hatfull GF. Bacteriophage Genomics. Curr Opin Microbiol. 2008;11:447-53. 
101. Groth AC, Calos MP. Phage integrases: biology and applications. J Mol Biol. 2004;16:667-78.

102. Campbell A. Prophage insertion sites. Res Microbiol. 2003;154:277-82.

103. Byl CV, Kropinski AM. Sequence of the genome of Salmonella bacteriophage P22. J Bacteriol. 2000;182:6472-81.

104. Efrony R, Atad I, Rosenberg E. Phage therapy of coral white plague disease: properties of phage BA3. Curr Microbiol. 2009;58:139-45.

105. Summer EJ, Enderle CJ, Ahern SJ, Gill JJ, Torres CP, Appel DN, Black MC, Young R, Gonzalez CF. Genomic and biological analysis of pahge Xfas53 and releated prophages of Xylella fastidiosa. J Bacteriol. 2010;192:179-90.

106. Liu M, Gingery M, Doulatov SR, Liu Y, Hodes A, Baker S, Davis P, Simmonds M, Churcher C, Mungall K, Quail MA, Preston A, Harvill ET, Maskell DJ, Eiserling FA, Parkhill J, Miller JF. Genomic and genetic analysis of Bordetella bacteriophages encoding reverse transcriptasemediated tropism-switching cassettes. J Bacteriol. 2004;186:1503-17.

107. Summer EJ, Gonzalez CF, Bomer M, Carlile T, Embry A, Kucherka AM, Lee J, Mebane L, Morrison WC, Mark L, King MD, LiPuma JJ, Vidaver AK, Young R. Divergence and mosaicism among virulent soil phages of the Burkholderia cepacia complex. J Bacteriol. 2006;188:255-68.

108. Zhu J, Rao X, Tan Y, Xiong K, Hu Z, Chen Z, et al. Identification of lytic bacteriophage $\mathrm{MmP1}$, assigned to a new member of T7-like phages infecting Morganella morganii. Genomics. 2010;96:167-72.
109. Oliveira H, Pinto G, Oliveira A, Noben JP, Hendrix H, Lavigne R, et al. Characterization and genomic analyses of two newly isolate Morganella phages defines distant members amongst Tevenvirina and Autographivirinae subfamilies. Sci Rep. 2017;7:46157.

110. Morozova V, Kozlova Y, Shedko E, Babkin I, Kurishikov A, Bokovaya O, et al. Isolation and characterization of a group of new Proteus bacteriophages. Arch Virol. 2018;163:2189-97.

111. Oliveira H, Pinto G, Hendrix H, Noben JP, Gawor J, Kropinski AM, et al. A lytic Providencia rettgeri virus of potential therapeutic values is a deep-branching member of the T5virus genus. Appl Environ Microbial. 2017:83:e01567-e1617.

112. Díaz-Muñoz SL. Viral coinfection is shaped by host ecology and virusvirus interactions across diverse microbial taxa and environments. Virus Evol. 2018;3:vex011.

113. Kupczok A, Neve H, Huang KD, Hoeppner MP, Heller KJ, Franz CMAP, Dagan T. Rates of mutation and recombination in Siphoviridae phage genome evolution over three decades. Mol Biol Evol. 2018;35:1147-59.

\section{Publisher's Note}

Springer Nature remains neutral with regard to jurisdictional claims in published maps and institutional affiliations.
Ready to submit your research? Choose BMC and benefit from:

- fast, convenient online submission

- thorough peer review by experienced researchers in your field

- rapid publication on acceptance

- support for research data, including large and complex data types

- gold Open Access which fosters wider collaboration and increased citations

- maximum visibility for your research: over $100 \mathrm{M}$ website views per year

At BMC, research is always in progress.

Learn more biomedcentral.com/submissions 